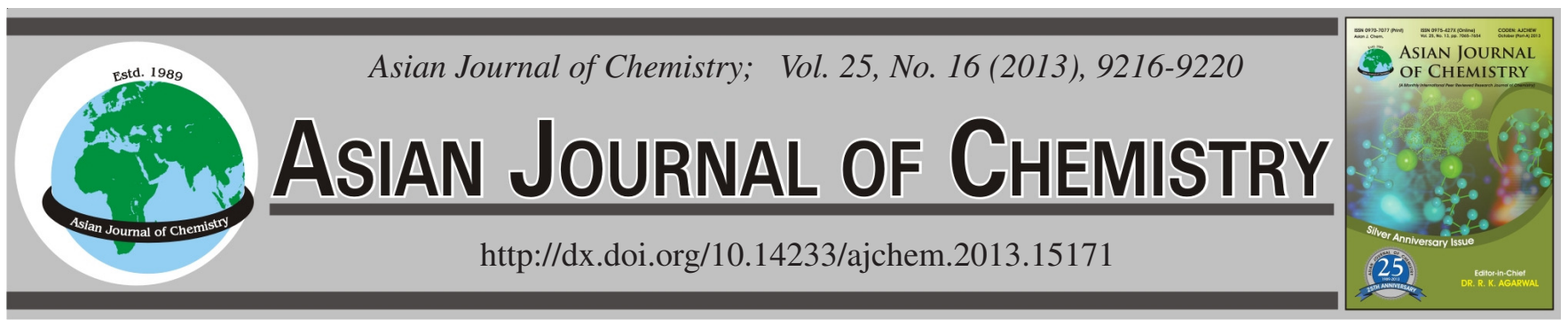

\title{
Vortex-Shaking-Assisted and Supramolecular Solvent-Based Microextraction Followed by HPLC-FLD Determination of Benzo(a)pyrene in Water Samples
}

\author{
Wenliang He, Xujia Hu, Zonghao Li, Xiaoshuang Chen and Mousheng Liu*
}

Faculty of Life Science and Technology, Kunming University of Science and Technology, Kunming, P.R. China

*Corresponding author: Tel: +86 13888284022; E-mail: hewenliangg@126.com; lmsh128@sina.com

\begin{abstract}
A supramolecular solvent made up of nonanoic acid aggregates is proposed for the extraction and reconcentrating of benzo(a)pyrene in water sample. The procedure involved the extraction of water sample $(9 \mathrm{~mL})$ with the supramolecular solvent made up of $250 \mu \mathrm{L}$ nonanoic acid and $1 \mathrm{~mL}$ tetrahydrofuran. Vortex-shaking was applied to enhance the extraction efficiency. Parameters affecting the extraction of target analytes including the selection of the alkylcarboxylic acid, the percentage of tetrahydrofuran, the amount of decanoic acid, temperature, extraction time and centrifuging time were investigated. Under the optimum conditions, the linear range of benzo(a)pyrene was $10-800 \mathrm{ng} \mathrm{mL}^{-1}$, the correlation coefficient of the calibration curves was 0.9999 , the relative standard deviations $(\mathrm{RSD}, \mathrm{n}=5)$ were $1.44-4.79 \%$ and the limits of detection (LOD) was $4.1 \mathrm{ng} \mathrm{mL}^{-1}$ in water samples. The results indicated that the method is simple and rapid, while delivering accurate and precise results and can be used for the determination of benzo(a)pyrene in water samples.
\end{abstract}

Key Words: Supramolecular solvent, Reverse micelles, Microextraction, Benzo(a)pyrene, Fluorescence detection.

\section{INTRODUCTION}

Benzo(a)pyrene (BaP) (Fig. 1), a polycyclic aromatic hydrocarbon, which is constitute a major environmental contaminant is usually generated through the combustion of fossil fuels or wood and is notably found in automobile exhaust, cigarette smoke, charcoal-boiled-foods and industrial waste by-products ${ }^{1}$. Benzo(a)pyrene can usually be found at very low concentrations in the environment ${ }^{2}$. Since they are hydrophobic and their persistence in the environment is mainly due to their low water solubility ${ }^{3}$.They can become a potential environmental problem and human health risk even at trace levels ${ }^{4}$. Therefore, an extraction and preconcentration technique is required prior to instrumental analysis for trace benzo(a)pyrene.<smiles>c1ccc2c(c1)cc1ccc3cccc4ccc2c1c34</smiles>

Fig. 1. Chemical structure of benzo(a)pyrene

The most commonly techniques used for determination of benzo(a)pyrene are high performance liquid chromatography with fluorescence detection (HPLC-FLD) ${ }^{5}$ and gas chroma- tography with mass spectrometry (GC-MS $)^{6}$. These methods are still difficult because the content of benzo(a)pyrene is very low, such as ng level or pg level in water ${ }^{7}$. Therefore, preconcentration techniques are often required. Liquid-liquid extraction $(\mathrm{LLE})^{5}$, liquid-phase microextraction (LPME) ${ }^{8}$, solid-phase extraction (SPE) $)^{9,10}$, solid-phase microextraction (SPME) $)^{11-14}$, liquid membrane extraction (LME) $)^{15,16}$ and cloud-point extraction $(\mathrm{CPE})^{17,18}$ have been developed to separate and concentrate the trace levels of benzo(a)pyrene in the environmental water samples.

Supramolecular solvents (SUPRASs) is a recent term ${ }^{19}$ to refer to nano-structured liquids generated from amphiphiles through a sequential, self-assembly process occurring on two scales, molecular and nano. This process gives, at first, threedimensional aggregates that coacervate, in a second stage, producing water immiscible liquids made up of large supramolecular aggregates dispersed in a continuous phase, generally water.

Supramolecular solvent-based extraction (SUSME) technique was initially proposed by Watanabe and co-workers ${ }^{20}$ on the basis of micellar coacervates produced by increasing the temperature of aqueous solutions of non-ionic micelles above a certain value (cloud point). Alkylcarboxylic acid-based solvents have been demonstrated to effectively extract substances in a wide polarity range from environmental ${ }^{21-26}$, biological $^{27}$ and food matrices ${ }^{28-30}$. For alkylcarboxylic acid- 
based supramolecular presence of different polarity regions in the supramolecular aggregates provide excellent solvation properties for a variety of organic and inorganic compounds. Their high extraction capability is explained on the basis of the different interaction mechanisms they provide to solubilize analytes and the high concentration of biosurfactant molecules they contain. Other valuable features are low-cost, experimental convenience (i.e., supramolecular solvents are produced at room temperature using conventional laboratory equipments) and rapidity (i.e., extractions are performed in a few minutes).

The SUPRAS proposed in this article for the extraction of benzo(a)pyrene was produced from an isotropic solution of reverse micelles of nonanoic acid in tetrahydrofuran (THF) by addition of water. The variables affecting the efficiency of the supramolecular solvent-based microextraction (SUSME) were studied, the analytical features of the proposed SUSMEHPLC-FLD methods were evaluated and both approaches were applied to the determination of benzo(a)pyrene in non-spiked and spiked environment water samples.

\section{EXPERIMENTAL}

All the reagents used were of analytical reagent grade and double distilled water was used as experimental water throughout the research. Nonanoic acid was obtained from Sigma (St. Louis,USA). Hydrochloric nonanoic acids and tetrahydrofuran and acetonitrile were purchased from Fengchuan Chemical Reagent Science and Technology Co.Ltd. (Tianjin, China). The standards of benzo(a)pyrene were purchased from National Institute for the Control of Pharmaceutical and Biological Products (Beijing, China) and were used with further purification.

The stock solutions of benzo(a)pyrene were prepared in acetonitrilel. They were all stored at $4{ }^{\circ} \mathrm{C}$ in the dark and can be stable for one month. The working solutions were obtained by appropriate dilution of the stock solutions with acetonitrile.

The chromatographic analysis was performed on an Agilent 1100 HPLC system (Agilent Technologies, Palo Alto, CA, USA), equipped with a quatpump, an auto injector and a fluorescence detector (FLD). A personal computer equipped with an Agilent ChemStation program for LC was used to process chromatographic data. The analytes were separated on Agilent $\mathrm{Tc}_{18}$ column $(150 \mathrm{~mm} \times 4.6 \mathrm{~mm}$; i.d.: $5 \mu \mathrm{m})$, which was bought from Agilent Technologies Inc. A centrifuge calibrated centrifugal tubes (Shanghai, China) was used for the phase separation process. Sample centrifugation was carried out with a model H-1650 centrifuge (Xiangyi Centrifuge Instrument Co., Ltd., Changsha, China). A Model MixPlus vortex mixer (Hefei, China) was also used.

$250 \mu \mathrm{L}$ nonanoic acid was dissolved with $1 \mathrm{~mL}$ of THF in centrifugation tube and mixed $30 \mathrm{~s}$ by vortex. Afterwards, a $9 \mathrm{~mL}$ water sample was added. The addition of the sample induced the formation of a water immiscible SUPRAS. The mixture was vortex-shaking for $2 \mathrm{~min}$ and centrifugated at $2500 \mathrm{rpm}$ for $15 \mathrm{~min}$ to speed up the complete separation of the supramolecular extract. An aliquot of the extraction, which was standing at the top of the solution in the centrifugation tubes, The aqueous phase was removed and the supramolecular extract phase was deposited at the bottom of the tube, then the extract phase was diluted to $0.5 \mathrm{~mL}$ with acetonitrile and $10 \mu \mathrm{L}$ of solution withdrawn using a microsyringe and transferred to inject into the HPLC system for analysis.

Detection method: The quantification was done by the evaluation of peak areas. The mobile phase was a mixture of acetonitrile-water (85:15, volume ratio) and the flow rate was $1.0 \mathrm{~mL} \mathrm{~min}^{-1}$. The column temperature was $30^{\circ} \mathrm{C}$ and the FLD detector excitation (Ex) and emission (Em) wavelength was set at 290 and $430 \mathrm{~nm}$ and the injection volume was $10 \mu \mathrm{L}$.

\section{RESULTS AND DISCUSSION}

In order to obtain the best analytical performance, the influence of different experimental parameters including the selection of the alkylcarboxylic acid, the percentage of THF, the amount nonanoic acid, temperature, extraction time, sample $\mathrm{pH}$ and centrifuging time were optimized. The recovery was used to evaluate the extraction efficiency under different experimental conditions. In this experiment, $9 \mathrm{~mL}$ of prepared mineral water sample spiked with $400 \mathrm{ng} \mathrm{mL}^{-1}$ of benzo(a)pyrene was used for the study.

Selection of the SUPRAS: With the objective of developing an effective approach for extracting benzo(a)pyrene in environment waters, SUPRASs obtained from the alkyl carboxylic acids (ACAs) octanoic acid, nonanoic acid, decanoic acid, undecanoic and dodecanoic acid were tested. These SUPRASs were generated from solutions of reverse micelles of alkyl carboxylic acids in THF by the addition of water sample with the $\mathrm{pH}$ adjusted at a value equal or below 4. At higher $\mathrm{pH}$ values, the solubilisation of deprotonated alkyl carboxylic acid molecules $(\mathrm{pKa}=4.8 \pm 0.2)$ in the water-THF phase in equilibrium with the SUPRASs occurred and that resulted in the formation of less volume of SUPRAS.

Fig. 2 depicts the recoveries obtained for benzo(a)pyrene from different alkyl carboxylic acids.The results showed that nonanoic acid exhibited the highest extraction efficiency of benzo(a)pyrene compared to the other acid. Therefore, nonanoic acid was selected as the extraction solvent for subsequent research.

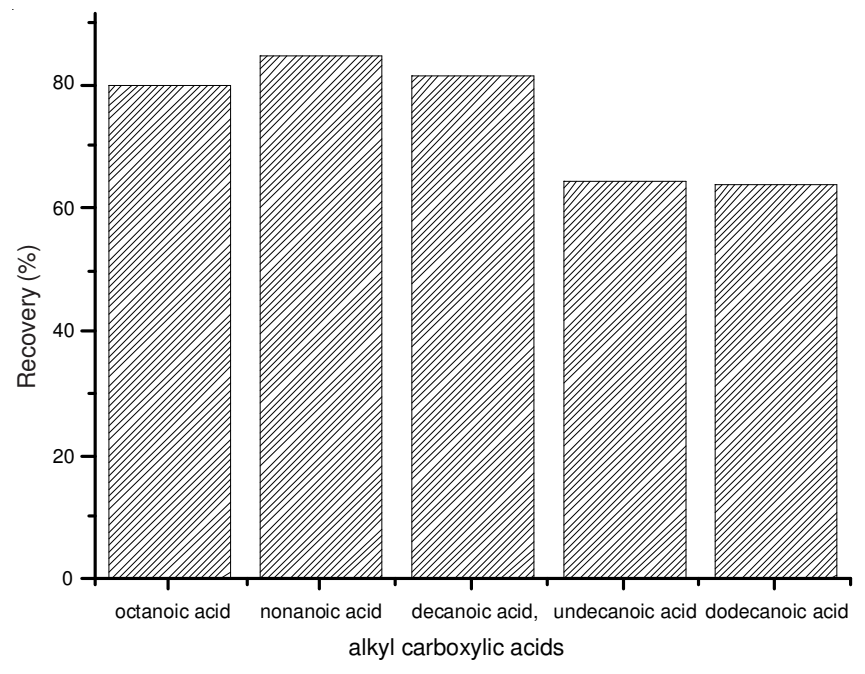

Fig. 2. Effect of different alkyl carboxylic acids on the extraction efficiency. Extraction conditions: sample volume, $9.0 \mathrm{ml}$; THF concentration: $8 \%$; the amount nonanoic acid: $200 \mu \mathrm{L}$. equilibration time: 10 min; equilibration temperature: room temperature; centrifuging rotation/rate: $4000 \mathrm{rpm}$; centrifuging time: $10 \mathrm{~min}$ 
Effect of the amount of nonanoic acid: The amounts of nonanoic acid is a critical factor for effective extraction and should be sufficient for quantitative extraction of the target analytes. Fig. 3 shows the influence of the amounts of nonanoic acid used to extract benzo(a)pyrene on the recovery from water sample. the peak areas of the benzo(a)pyrene was increased when amounts of nonanoic acid was increased from 50-300 $\mu \mathrm{L}$. Then the peak areas were slightly decreased when the amounts of nonanoic acid was further increased till $500 \mu \mathrm{L}$. Therefore, $250 \mu \mathrm{L}$ nonanoic acid was selected as optimum concentration.

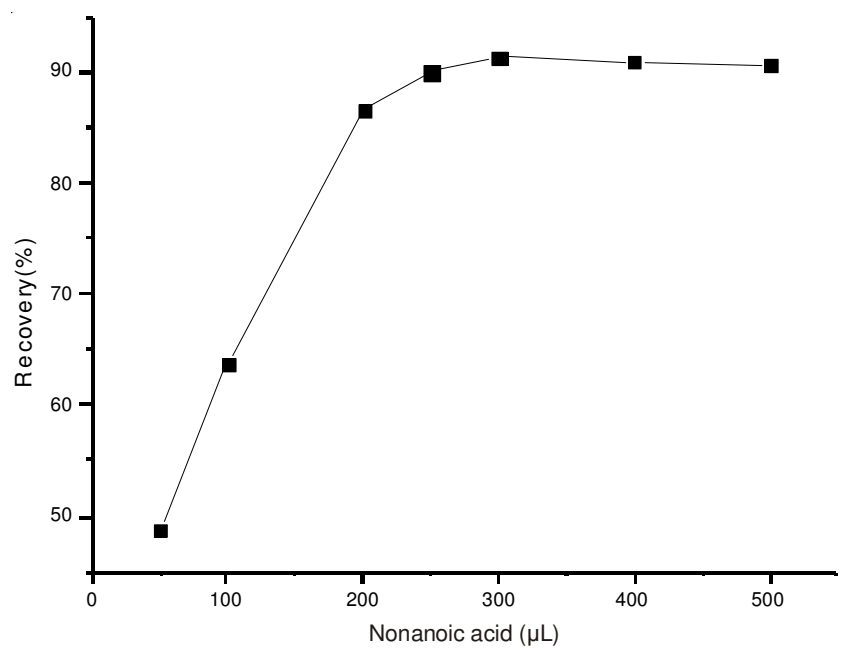

Fig. 3. Effect of the amount nonanoic acid on the extraction efficiency. sample volume, $9.0 \mathrm{~mL}$; THF concentration: $8 \%$; equilibration time, $10 \mathrm{~min}$; equilibration temperature: room temperature; centrifuging rotation/ rate: $4000 \mathrm{rpm}$; centrifuging time: $10 \mathrm{~min}$

Effect of the percentage of THF: Fig. 4 shows the recoveries obtained for benzo(a)pyrene as a function of the percentage of THF and, the increase in the amount of THF resulting an increasing recovery. A THF concentration of $10 \%$, which permitted to obtain recoveries above $90 \%$, was selected as optimal.

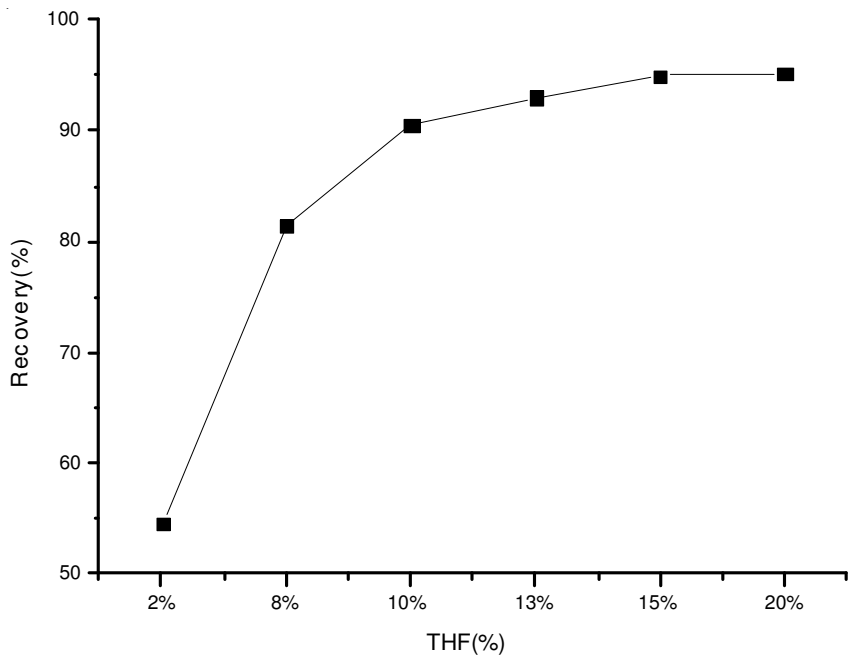

Fig. 4. Effect of percentage of THF on the extraction efficiency. sample volume: $9.0 \mathrm{~mL}$; THF concentration: $10 \%$; the amount nonanoic acid, $250 \mu \mathrm{L}$. equilibration time: $10 \mathrm{~min}$; equilibration temperature: room temperature; centrifuging rotation/rat: $4000 \mathrm{rpm}$ centrifugingtime: $10 \mathrm{~min}$
Effect of equilibration temperature and time: Extractions performed by vortex-shaking assistant and room temperature reached equilibrium conditions in about $10 \mathrm{~min}$. The extraction time for quantitative recovery was not reduced by increasing the vortex-shaking time above this value (Fig. 5).

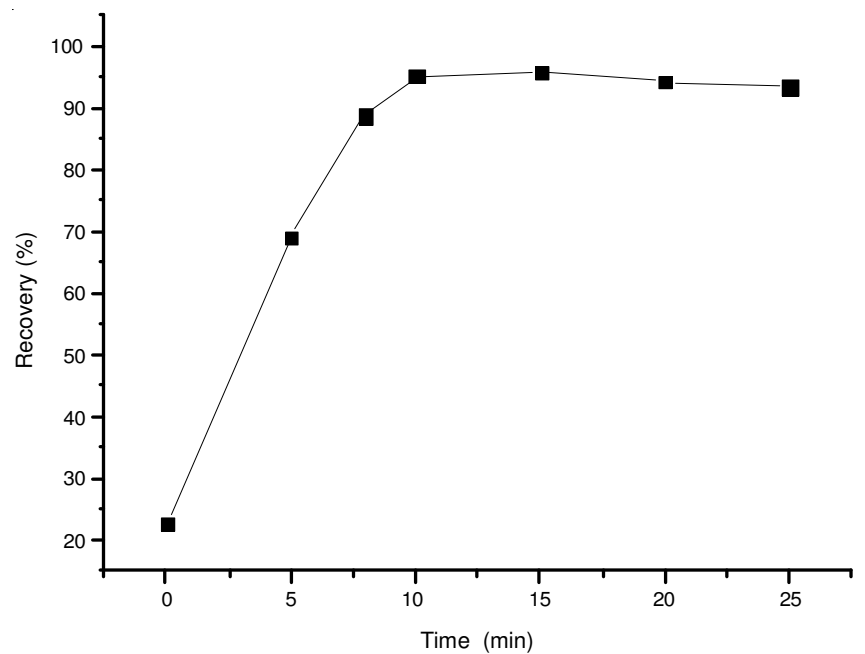

Fig. 5. Effect of centrifuging time on the extraction efficiency. sample volume: $9.0 \mathrm{~mL}$; THF concentration: $10 \%$; the amount nonanoic acid: $250 \mu \mathrm{L}$; equilibration time: $10 \mathrm{~min}$; equilibration temperature: room temperature; centrifuging rotation/rate: $4000 \mathrm{rpm}$; centrifuging time: $10 \mathrm{~min}$

The temperature did not affect the extraction efficiency of the supramolecular solvent, but decreased recoveries were obtained as it was increased above $40{ }^{\circ} \mathrm{C}$ due to the semi volatile of the analytes.

After the shaking-assisted extraction of samples, the liquid extract was separated from the non-soluble matrix components by ultracentrifugation using different rotation rates and times. Centrifugation of the sample at $2500 \mathrm{rpm}(9 \mathrm{~mL})$ for $15 \mathrm{~min}$ is recommended. Lower rotation rates/times of centrifugation did not provide an effective separation of sample particles from the supramolecular extract.

Analytical performance: The analytical features of merit of the method for the determination of the target benzo(a)pyrene are shown in Table-1. Calibrations curves were run using standard solutions prepared in acetonitrile. Since no differences in peak areas or retention times were observed for the analytes injected in organic solvent or SUPRAS.

The practical detection limits were calculated from benzo(a)pyrene of blank river and underground water samples by using a signal-to-noise ratio of 3 (the ratio between the peak areas for benzo(a)pyrene and peak area of noise). Since no significant differences in the noise measured for river and underground water were observed, the same detection limits were obtained for both type of samples (Table-1); no differences among recoveries obtained. No significant differences in the noise measured for river and underground water were observed.

The possible interference of matrix components was assessed by comparison of the slopes of the calibration curves $(n=7)$ obtained from standards in distilled water with those obtained from river and underground water samples fortified with known amounts of benzo(a)pyrene and run using 
TABLE-1

PERFORMANCE CHARACTERISTICS OF THE PROPOSED METHOD

\begin{tabular}{cccccc}
\hline Analyte & Linear range $(\mathrm{ng} / \mathrm{mL})$ & Regression equation & Correlation coefficient & LOD $(\mathrm{ng} / \mathrm{mL})$ & $\mathrm{RSD}(\%)(\mathrm{n}=5)$ \\
\hline Benzo(a)pyrene & $10-800$ & $\mathrm{y}=245580 \mathrm{x}+333.63$ & 0.9999 & 4.1 & 0.87 \\
\hline
\end{tabular}

the whole procedure. The slopes of the calibration curves performed in distilled water were $245580 \pm 150$, no statistically significant differences between these slopes and those obtained from the samples (two river and three underground water samples) were observed by applying a student test ${ }^{31}$. Therefore, matrix components were not expected to interfere in the determination of the target analytes.

The precision of the proposed method was assessed by analyzing water samples independently spiked with benzo(a)pyrene at three concentration levels (50, 400 and 800 $\left.n g \mathrm{~L}^{-1}\right)$. And the relative standard deviations $(\mathrm{n}=5)$ varied within the intervals $1.44-4.79 \%$.

Analysis of water samples: To prove the feasibility of the method to determine benzo(a)pyrene in natural waters, both non-fortified and fortified samples from tap water, Dianchi Lake and miner water were analyzed. No benzo(a)pyrene were detected in the non-spiked samples. Results obtained for samples fortified with benzo(a)pyrene at three concentration levels are listed in Table-2. Apparent recoveries ranged in the intervals $90.78-103.42 \%$, with standard deviations of the per cent recovery varying between 1 and $4 \%$. Figs. 6-8 show the chromatogram obtained from both non-fortified and fortified tap water, Dianchi Lake and miner water sample, respectively.

\begin{tabular}{|c|c|c|c|c|}
\hline \multicolumn{5}{|c|}{$\begin{array}{c}\text { TABLE-2 } \\
\text { ANALYTICAL RESULTS FOR BENZO(a)PYRENE } \\
\text { IN WATER SAMPLES }\end{array}$} \\
\hline $\begin{array}{l}\text { Sample } \\
\text { location }\end{array}$ & $\begin{array}{l}\text { Spiked } \\
(\mathrm{ng} / \mathrm{L})\end{array}$ & $\begin{array}{l}\text { Found } \\
(\mathrm{ng} / \mathrm{L})\end{array}$ & Recovery & $\begin{array}{c}\operatorname{RSD}(\%) \\
(\mathrm{n}=5)\end{array}$ \\
\hline \multirow{4}{*}{ Tap water } & 0 & $\mathrm{ND}^{\mathrm{a}}$ & - & - \\
\hline & 50 & 51.63 & 103.27 & 1.49 \\
\hline & 400 & 395.00 & 98.75 & 3.27 \\
\hline & 800 & 44.88 & 93.11 & 4.69 \\
\hline \multirow{4}{*}{$\begin{array}{l}\text { Dianchi } \\
\text { river }\end{array}$} & 0 & $\mathrm{ND}^{\mathrm{a}}$ & - & - \\
\hline & 50 & 50.04 & 100.08 & 1.44 \\
\hline & 400 & 363.12 & 90.78 & 2.38 \\
\hline & 800 & 829.69 & 103.26 & 4.79 \\
\hline \multirow{4}{*}{$\begin{array}{l}\text { Mineral } \\
\text { water }\end{array}$} & 0 & $\mathrm{ND}^{\mathrm{a}}$ & - & - \\
\hline & 50 & 46.17 & 92.33 & 3.56 \\
\hline & 400 & 413.68 & 103.42 & 1.66 \\
\hline & 800 & 56.40 & 94.55 & 1.78 \\
\hline
\end{tabular}

\section{Conclusion}

The microextraction of benzo(a)pyrene from water with the supramolecular solvent made up of reverse micelles of nonanoic acid constitutes a valuable alternative to the current methodologies, which based on the use of solvent. Consequently, actual concentration factors around 50-100 are
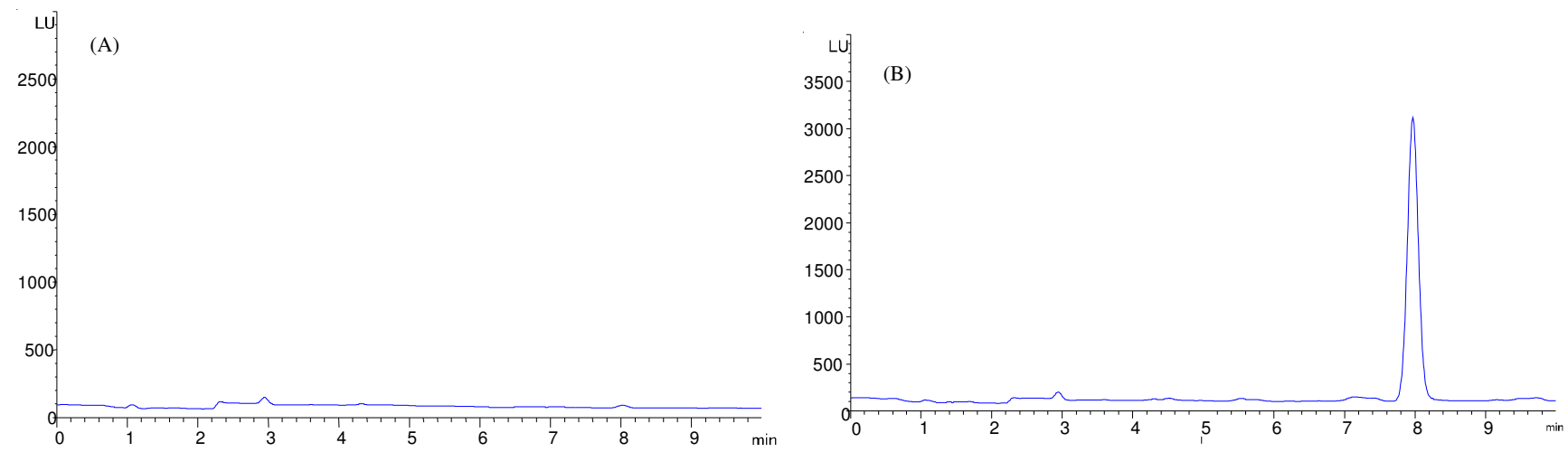

Fig. 6. Chromatograms of tap water sample obtained by SUSME under optimal condition (A) spiked sample with $100 \mu \mathrm{gg} / \mathrm{L}$ (B) sample not spikted
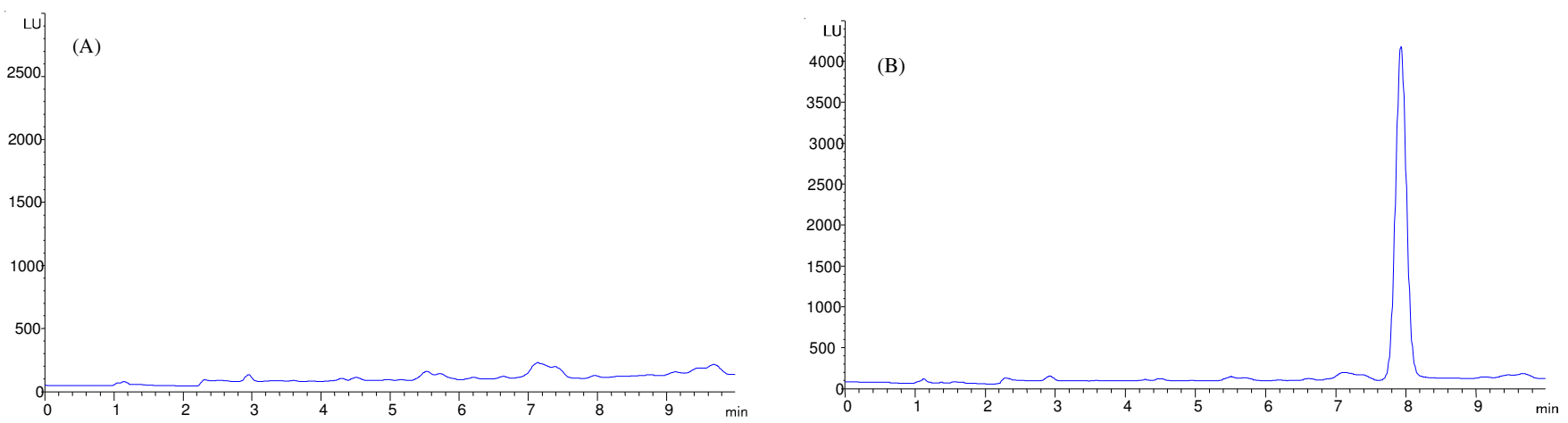

Fig. 7. Chromatograms of water sample of Dianchi Lake obtained by SUSME under optimal condition (A) spiked sample with $100 \mu \mathrm{g} / \mathrm{L}$ (B) sample not spikted 

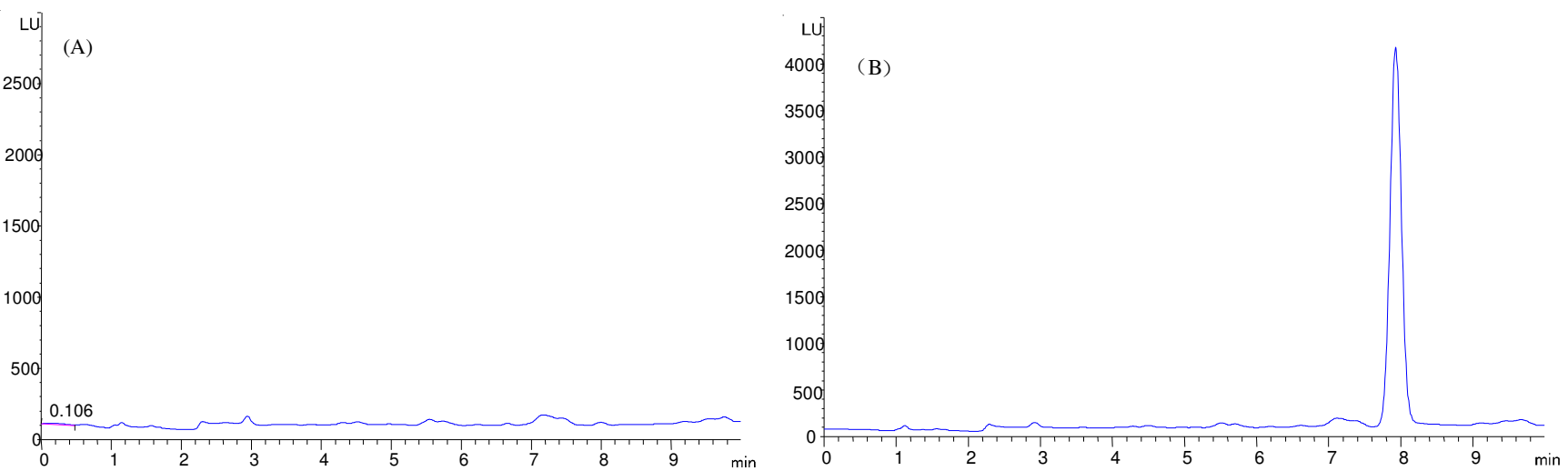

Fig. 8. Chromatograms of and mineral water sample obtained by SUSME under optimal condition (A) spiked sample with $100 \mu \mathrm{gg} / \mathrm{L}$ (B) sample not spikted

easily obtained using a single-step extraction without solvent evaporation. Equilibrium conditions are rapidly established and the whole extraction takes $0.5 \mathrm{~h}$ and several samples can be simultaneously extracted, so the sample throughput will mainly depend on the chromatographic analysis of the target compounds.

\section{ACKNOWLEDGEMENTS}

The work was supported by the Natural and Science Foundation of Yunnan Province (2010ZC027) and the Analysis and Testing Foundation of Kunming University of Science and Technology (No. 20130430).

\section{REFERENCES}

1. A. Ene, O. Bogdevich, A. Sion and T. Spanos, Microchem. J., 100, 36 (2012).

2. W.D. Wang, Y.M. Huang,W.Q. Shu and J. Cao, J. Chromatogr. A, 1173, 27 (2007).

3. M.T. Alcántara, J. Gómez, M. Pazos and M.A. Sanromán, Chemosphere, 70, 1438 (2008).

4. P. Kuesen, C. Thammakhet, P Thavarungkul and P. Kanatharana, Microchem. J., 96, 317 (2010).

5. A. Ishizaki, K. Saito, N. Hanioka, S. Narimatsu and H. Kataoka, $J$. Chromatogr. A, 1217, 5555 (2010).

6. J.B. Beach, E. Pellizzari, J.T. Keever and L. Ellis, J. Anal. Toxicol., 24, 670 (2000).

7. E. Manoli and C. Samara, Trends Anal. Chem., 18, 417 (1999).

8. S. Shariati-Feizabadi, Y. Yamini and N. Bahramifar, Anal. Chim. Acta, 489, 21 (2003).

9. R.M. Marce and F. Borrull, J. Chromatogr. A, 885, 273 (2000).

10. E.B. Aziza, K. Anders and A.R. Mohamed, J. Chromatogr. A, 1114 $234(2003)$
11. A. Kabir, C. Hamlet, K.S. Yoo, G.R. Newkome and A. Malik, J. Chromatogr. A, 1034, 1 (2004)

12. H. Bagheri and A. Salemi, Chromatographia, 59, 501 (2004).

13. A. Mohammadi, Y. Yamini and N. Alizadeh, J. Chromatogr. A, 1063, 1 (2005).

14. A.J. King, J.W. Readman and J.L. Zhou, Anal. Chim. Acta, 523, 259 (2004).

15. L. Zhao and H.K. Lee, Anal. Chem., 74, 2486 (2002).

16. S. King, J. Meyer and A. Andrews, J. Chromatogr. A, 982, 201 (2002).

17. J.L. L and B.H. Chen, J. Colloid Interf. Sci., 263, 625 (2003).

18. T.I. Sikalos and E.K. Paleologos, Anal. Chem., 77, 2544 (2005).

19. A. Ballesteros-Gómez, S. Rubio and D. Pérez-Bendito, J. Chromatogr. A, 1216, 530 (2009).

20. H. Ishii, J. Miuraand and H. Watanabe, Bunseki Kagaku, 26, 252 (1997).

21. F.J. Ruiz, S. Rubio and D. Pérez-Bendito, Anal. Chem., 78, 7229 (2006).

22. F.J. Ruiz, S. Rubio and D. Pérez-Bendito, Anal. Chem., 79., 7473 (2007).

23. F.J. Ruiz, S. Rubio and D. Pérez-Bendito, J. Chromatogr. A, 1163, 269 (2007).

24. A. Moral, M.D. Sicilia and S. Rubio, J. Chromatogr. A, 1216, 3740 (2009).

25. A. Ballesteros-Gómez, F.J. Ruiz, S. Rubio and D. Pérez-Bendito, Anal. Chim. Acta, 603, 51 (2007).

26. A.M. Ballesteros Gómez, S. Rubio and M.D. Pérez-Bendito, J. Chromatogr. A, 1203, 168 (2008).

27. A. Garcia Prieto, M.L. Lunar, S. Rubio and M.D. Pérez-Bendito, Anal. Chim. Acta, 630, 19 (2008)

28. A. García-Prieto, L. Lunar, S. Rubio and D. Pérez-Bendito, Anal. Chim. Acta, 617, 51 (2008).

29. S. García Fonseca, A.M. Ballesteros Gómez, S. Rubio and M.D. PérezBendito, Anal.Chim. Acta, 617, 3 (2008).

30. A.M. Ballesteros Gómez, S. Rubio and M.D. Pérez-Bendito, J. Chromatogr. A, 1216, 530 (2009)

31. L. Cuadros, A.M. García, F. Alés, C. Jiménez and M. Román, J. AOAC Int. . 78, 471 (1995). 